\title{
Routine exposures: reimaging the visual politics of hazardous sites
}

\author{
Angeliki Balayannis \\ Brunel University London
}

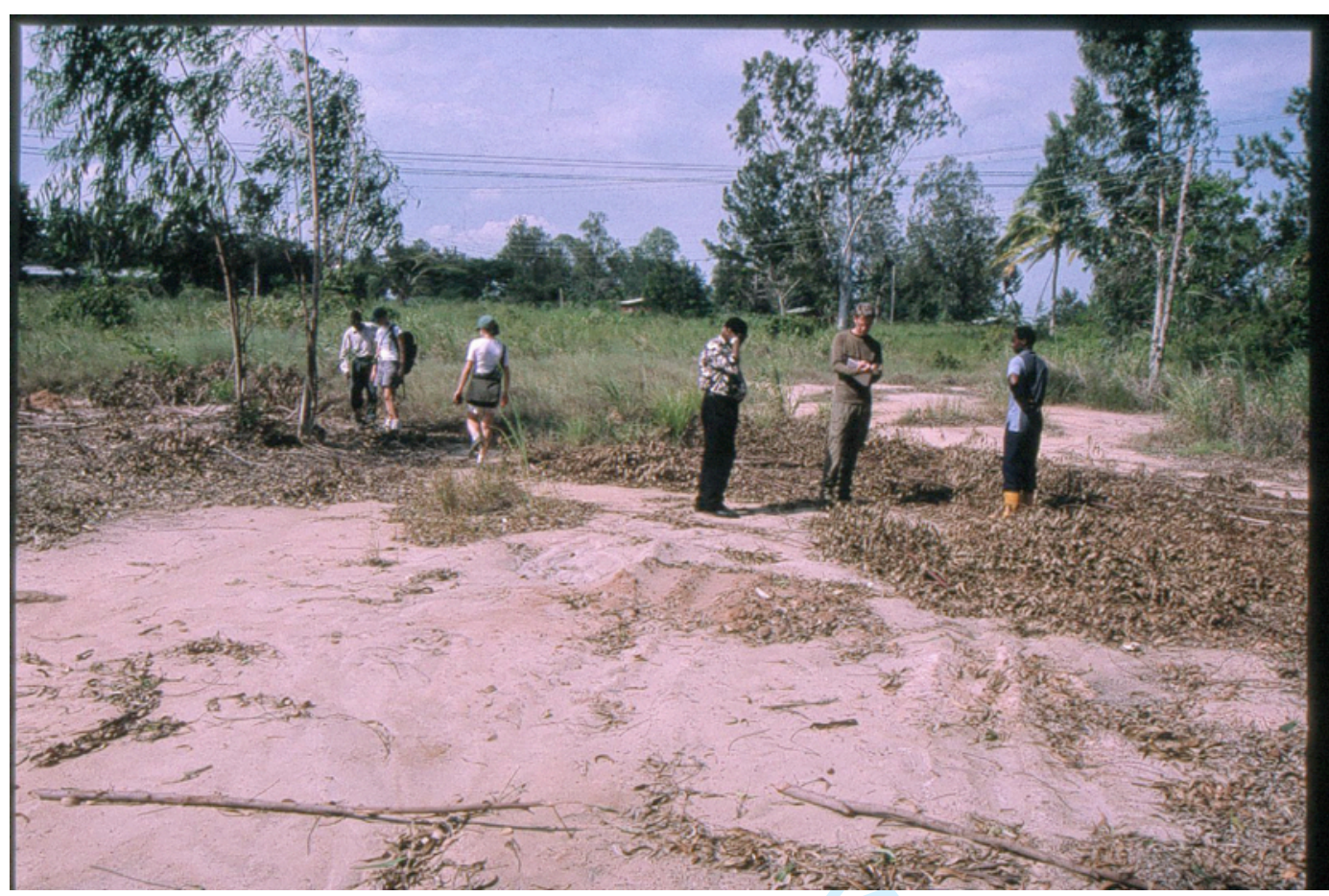

Figure 1. 2002. Environmental chemists undertaking fieldwork at a contaminated site in Vikuge, Tanzania. Photographer: Henrik Kylin (chemist). Source: scanned copy from Henrik's research archive in Bromölla, Sweden.

\section{HAZARDOUS SIGHTS}

This paper aims to photographically reimagine the representation of hazardous sites. It examines disregarded worlds of mundane yet politically vital photography: procedural representations made and circulated in hazardous site interventions. Scholarship which examines the visualisations of hazardous sites remains largely concerned with professional photography and sublime aesthetic registers. This photo essay departs from this epistemological habit and examines the visualities and materialities of technical representations enacted in remediation and research processes. It approaches photographs through the practices in which they are made and circulated, occupying a more-thanrepresentational register that works to de-sensationalise hazardous site photography. These routine exposures unsettle naturalised ways of seeing contamination; they demonstrate how 
hazardous sites are made (in)visible and enable more situated understandings of the power of photography.

The object of concern is a chemical stockpile in coastal Tanzania. In 1986, around two hundred and twenty tonnes of obsolete dichlorodiphenyltrichloroethane -- better known as DDT -- were dumped on a state-owned hay farm in the village of Vikuge. The farm is pictured above, in one of dozens of photographs produced by an environmental chemist undertaking fieldwork at the site in 2002 (Figure 1). At the time the photograph was taken, Vikuge farm was one of the heaviest pesticide-contaminated sites in the world. For twentyseven years the stockpile of highly persistent pesticides had been exposed to the wind, sun, and rain, slowly moving and transforming across space and time. The pesticides accumulated and magnified in toxicity as they moved across food webs, up trophic levels, from one species to the next; from invertebrates in pond sediments, to fish, then birds, and eventually, to the bodies of humans (cf. Barbash 2014). These processes are unending and indeterminate, with a multitude of uncertain effects that span generations. However, these material geographies are difficult to see -- at least in terms of the visual tropes typically enrolled to politicise hazardous sites. There are no rusting steel drums, foaming rivers, hazard signs, plumes of smoke, or foreboding landscapes (e.g. Ray 2016; Rosenfeld et al. 2018). The dominant ways of visually representing contaminated sites are at odds with the elusive material properties and capacities of chemicals; bodily entanglements with materials such as DDT ultimately unfold beneath thresholds of perception (cf. Shapiro 2015).

Visual representations are a matter of concern within hazardous site geographies because they are central to the work of governing and managing disposal; they shape how sites are defined, politicised, and remediated (e.g. Pikner and Jauhiainen 2014; Liboiron 2015; Gabrys 2017). Yet despite their power, the photographs produced and circulated in disposal processes have been overlooked. Research on representations of hazardous sites remains largely enchanted with the capacities of photographs produced by professional photographers such as Edward Burtynsky and Sean Smith (e.g. Crang 2010; Ray 2016). The extant research is concerned with the aesthetics of the 'toxic sublime' and the capacity to shock audiences into action. This approach to understanding hazardous landscapes has been subject to forceful critique - the central concern being that the sublime can obfuscate the processes through which hazardoussites emerge (see Gatlin 2015; Rosenfeld et al. 2018). As a critical response, geographers are increasingly turning to more bureaucratic, ordinary, and processual representations to creatively question the status quo of hazardous site imaginaries (e.g. Anaïs and Walters 2016; Moore et al. 2017; Rosenfeld et al. 2018). Recent engagement with Mathieu Asselin's work, Monsanto -- A Photographic Investigation, particularly marks an important shift in aesthetic registers toward the mundane dimensions of life with chemicals (see Davies 2018), as does Richard Misrach and Kate Orff's Petrochemical America. However, my task in this paper is to move beyond concerns for professional photography.

This paper contributes to the unfolding turn towards the ordinary dimensions of extraordinary sites, however, unlike the emerging geographic scholarship, my concern with the visual in this paper is 'more-than-representational' (Lorimer 2005); I think with photographs through the practices and processes in which they are produced, circulated, and encountered. Through a photo essay, I approach photography as both object of analysis and research method, with the objective of performatively unsettling 'naturalised' ways of seeing (Rose and Tolia-Kelly 2012). In this way, the paper occupies both analytical and evocative registers; creating both an argument and a feeling (Rose 2016). The photographs assembled 
in this paper are images of the Vikuge stockpile routinely produced by public servants, technicians, and researchers -- including myself. These photographs emerged through multisited ethnographic research in which I 'followed' the lingering residues of the DDT stockpile in disposal (cf. Cook et al 2004; Gregson et al. 2010). The paper has two key sections: the first discusses the conceptual, methodological, and empirical form of this research; and the second offers three series of photographs, which coupled with ethnographic notes, tell a story of unending material transformation, and point to the pivotal role of photography in fieldwork. This approach decentres and multiplies the site as an object (cf. Law 2002), working to shift assumptions of what contaminated sites look like, and re-consider what kinds of images can be used to critically examine the toxic legacies of 20th century chemistry.

\section{FROM TOXIC SUBLIME TO ROUTINE VISION}

The visual and aesthetic dimensions of hazardous sites are largely dominated by debates over the 'toxic sublime'. The sublime is imagined as a genre which elicits transformative affective responses: awe, shock, amazement, and wonder (see Peeples 2011; Gatlin 2015; Ray 2016). The 'toxic' or 'industrial' sublime are often invoked as an aesthetic tactic for generating responses to environmental injustices -- shocking audiences into political action. Edward Burtynsky's spectacular photographs of industrial processes are a key example of this genre and his images have become a pivotal discussion point for visualising pollution and bearing witness to the violence of capitalism (e.g. Crang 2010; Giblett 2009; Gatlin 2015). Some of Burtynsky's most iconic photographs are his series on nickel mine tailings, which depict flaming orange contaminated rivers flowing through dark desolate fields (see Gatlin 2015). This way of seeing pollution is evocative, but it has epistemological limits and presents ethical concerns.

Most contaminated landscapes are not-so-obvious or pronounced in their visualities -indeed, this paper will demonstrate that the more explicit visual dimensions of hazardous sites do not necessarily represent the properties of contaminants in terms of their chemistry. A lingering question which underscores this literature is whether the sublime can represent the lived experiences of hazardous sites -- let alone catalyse political action. This form of photography has been criticised for fetishizing toxicants and aestheticizing hazardous sites in ways that obscure the broader processes though which waste is produced (Gatlin 2015; Conohar 2017). That said, (new) materialist engagements with photographs in this genre generate more affirmative analyses and arguments in a more-than-human register: Sarah Jaquette Ray (2016) argues Burtynsky's work offers a unique way of grasping the vibrant material transformations of industrial materials, and Mike Crang's $(2010 ; 2012)$ examination of ship breaking gestures to the ways the sublime can attend to the vast spatiotemporalities of global capitalism. However, at this point I wish to depart from engagements with the sublime -- not only because the critiques are well-rehearsed -- but because these literatures bear an enduring epistemological concern with the stuff of professional photography. There is a world of more mundane and less-circulated images that has hitherto been neglected.

Emerging visual geographies which privilege the ordinary and the 'everyday' (de Certau 1984) dimensions of hazardous sites, are demonstrating the critical capacities of photography without appealing to the sublime. This engagement with photography centres the experiences of those living and working at hazardous sites -- Thom Davies' (2013) 
research on the visual geographies of Chernobyl is a key example of this approach. Davies deploys 'participant photography' to understand the lives of those dwelling in Chernobyl, highlighting the importance of everyday life in apprehending the embodied politics of nuclear disaster. This is situated in a foundational approach to environmental justice research, which decentres hegemonic voices in order to privilege the experiences of affected communities (Houston 2013). However, the material properties and capacities of contaminants and their more-than-human entanglements, are largely overlooked in environmental justice accounts, or are reduced to the 'invisibility' of nuclear fallout. In effect, the invisible dimensions of industrial contaminants and their affects are naturalised in concerns with the everyday -- just as much as sublime representations naturalise the visible.

Photographs of life at hazardous sites are ultimately generated as a way of exposing the ir/responsibilities of industry and the state (e.g. Davies 2013; 2018), and so the representations forged by industry in these politically toxic landscapes are often reduced to their role in producing injustices. However, a growing literature concerned with hazardous aesthetics is demonstrating the critical capacities of working with the materials that might otherwise be dismissed as the stuff of 'greenwashing'. Waste management data is increasingly being used to create playfully subversive representations of disposal processes (e.g. Krupar 2013; Rosenfeld et al. 2018). This research disrupts dominant ways of seeing hazardous landscapes by re-assembling and re-interpreting their representations. Drawing on Sianne Ngai's (2012) aesthetic category of the 'merely interesting', Heather Rosenfeld and her colleagues (2018) imaginatively demonstrate how the ordinariness of hazardous waste management data -- reports, permits, and plans -- has a great capacity to be read otherwise. Their work on hazardous aesthetics is the intellectual point of departure for this photo essay. I extend their intervention by exploring site representations in a more-than-representational register. But in order to discuss methodological concerns, it is important to first return to the Vikuge stockpile.

\section{FOLLOWING A CHEMICAL STOCKPILE}

Like food, plastics, and electronics, pesticides have an afterlife. However, unlike these everyday commodities, pesticides cannot be composted, repaired, recycled, re-purposed, or sent to landfill. When they are banned or pass their date of expiry, pesticides legally become hazardous waste, and as a consequence, they often accumulate in vast stockpiles (see FAO 2005). Like all forms of hazardous waste, these stockpiles always located unevenly, with very uneven effects (cf. Nixon 2011). The Food and Agriculture Organization of the United Nations (2005) suggests obsolete pesticide stockpiles are predominantly located in lowincome counties, although a study of their distribution has yet to be conducted. These stockpiles have remained within the onto-epistemological purview of non-government and intergovernmental organisations (e.g. IPEN and AGENDA 2005; FAO 2005). The narrow and technical terms of reference in these accounts take the materialities of stockpiles for granted. And despite a growing attentiveness to worlds of industrial chemistry within the social sciences and humanities (Romero et al. 2017; Shapiro and Kirksey 2017), research on pesticides has yet to consider this commodity in its waste formations (e.g. Galt 2008; Davis 2014).

The stockpile of DDT arrived in Vikuge village in 1986, at the peak of a wave of hazardous waste dumping from European to African nations. Legal scholars imagine this period of waste trade in the 1980s and 1990s as 'toxic waste colonialism' (Pratt 2011). The 
stockpile is one of countless others like it across Tanzania and the rest of the continent. The Basel Convention, which now governs the transboundary movement of hazardous materials, was assembled in response to this kind of colonial flow of materials (see Clapp 2001). However, the extent to which these conventions work, or are relevant to contemporary waste flows is debated within geography (see Lepawsky 2015 on shifting waste flows). The stockpile remained at Vikuge farm for almost three decades before being removed for incineration in the south of Poland in 2013. But its removal was incomplete. What matters for this case is that the site continues to persist as material legacy of violent political economies that may well have radically shifted in terms of trade.

I traced the lingering residues of the Vikuge stockpile across time and space, through Tanzania, Greece, Poland, Sweden, Belgium and the United Kingdom. Its material biography was assembled by engaging with people and organisations that have worked with the stockpile throughout its disposal. This includes government agencies, chemical manufacturers, universities, non-governmental organisations (NGOs), and disposal companies. In this paper I attend to participants' visual practices with the afterlives of pesticides. Locating my analysis at the intersections of visuality and materiality enables a more situated understanding of how sites are made (in)visible (cf. Rose and Tolia-Kelly 2012). Embedded in this approach is an acknowledgement that the visual is also always entangled with other modes of sensing (Degen, DeSilvey, and Rose 2008). I assemble a collection of photographs sourced from archives, reports, and interviews with technicians and chemists -- including my own photographs from a tour of the site in early 2017.

Akin to fieldnotes, I approach photography as a method of apprehending the materialities of pesticide. The aesthetics of the images perform a secondary or more openended role in this form of photography (cf. Garrett 2014). I depart with the preference to assemble photo essays with 'good' photographs (Rose 2016, 324) -- indeed, the photographers which feature in this paper are not trained in photography, nor do they consider themselves to be photographers. Thinking with David Bissell's (2009) notion of 'attentive vision', these site visualisations are practices of specifically searching for markers of the stockpile's presence -- whether it be container fragments, powdery residues, or the lethal effects of exposure. These images are assembled because of their evidentiary power within site interventions. The photographs are produced for audits, attached in the annexes of dry technical reports, forgotten in unused computer folders, and on occasion furnish conference presentations.

Although the photographs are all encounters with the stockpile, these images rarely speak to each other -- nor do the photographers which produce them. The messy negotiation of disorderly and excessive pictures happens throughout fieldwork, however this has yet to be examined, apart from Harper's (2003) use of aerial images to speak with farmers. Drawing on John Law's (2002) methodological logic of the pinboard, this photo essay decentres the site as an object of analysis. Creating new juxtapositions expands the spatiotemporalities of this site, rendering the site multiple. The pages to come, stage an encounter between three sets of photographs of the Vikuge site to consider their connections and disjunctures. Each set has a different photographer, with different circuits of distribution, and different audiences. It is crucial to note that the photo is also just as important as the text -- the caption exponentially increases the power of the photograph as evidence (Berger 2013). The paper ultimately creates a space where the authority of photographs is unsettled to enable more richly textured and relational understandings of sites. 
My tour at Vikuge farm in early 2017 was the final leg of fieldwork following the elusive material geographies of this object. However, this was not my first encounter with the site. My engagement with the biography of this stockpile can be traced back to an essay I had written on pesticide contamination in Africa as an undergraduate. Years of research followed, culminating in my guided tour at Vikuge in January 2017. Photographs (and photographers) of the stockpile are always located in a discursive field, not revealing anything to their audience that they were not 'already primed to believe' (Sontag 2003, 9). My visit to the site was refracted through years of discussion and reading, piecing together the stockpile's lingering fragments. Indeed, all of this work was a precondition for being able to see anything exceptional at the site -- which otherwise appeared to be a pleasant clearing through which to take an afternoon stroll (Figure 2). In this way visiting Vikuge was like working on a palimpsest (Crang 1996). Through my own photographic practice, I re-made the mundane landscape photographs and quiet images of death that I had collected from participants over the previous years. My compulsion to witness was also fundamentally shaped by my guide, who as an environmental chemist was attuned to dead bodies as markers of toxicity. 


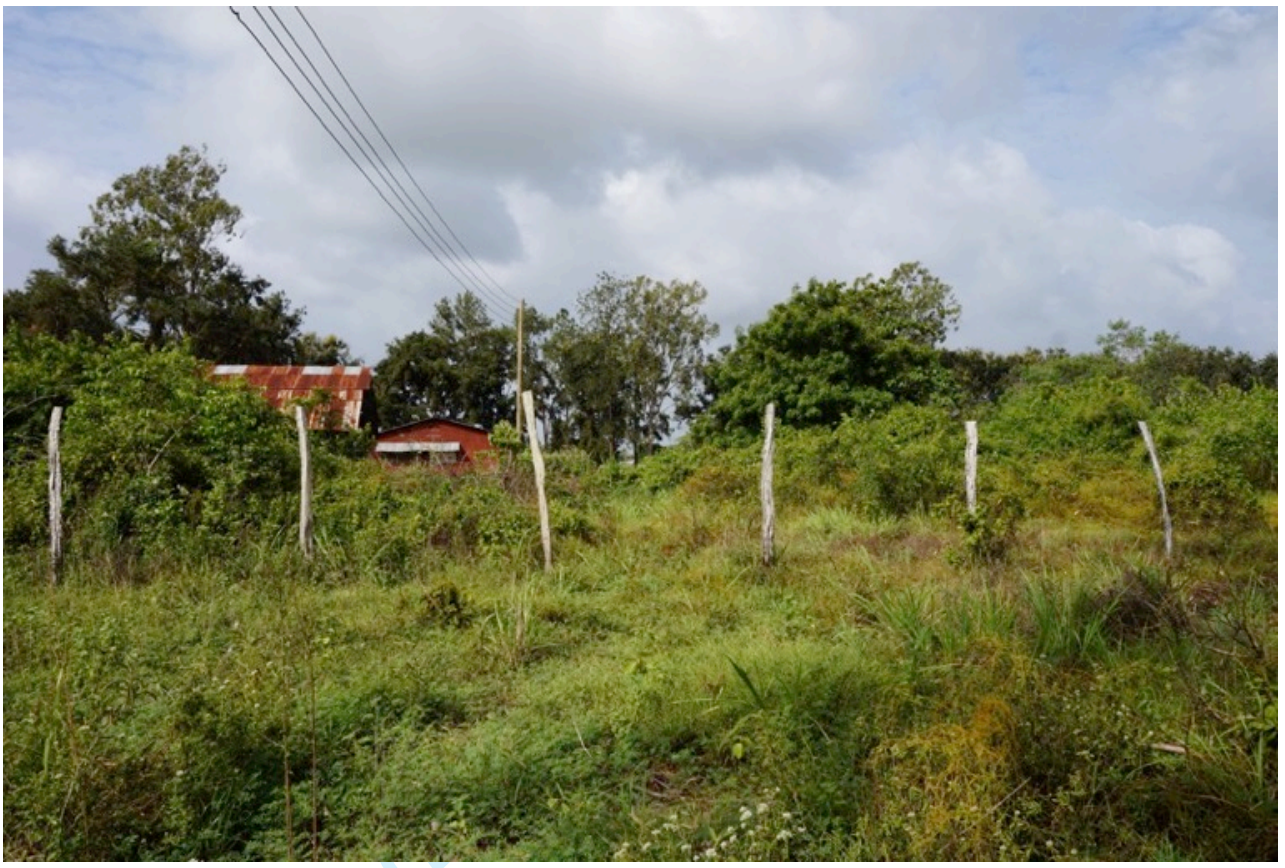

Figure 2. 2017. Wire and wooden fence at the perimeter of the pesticide stockpile site. Hay shed and farm administrative office in the background. Vikuge, Tanzania. Photographer: author.

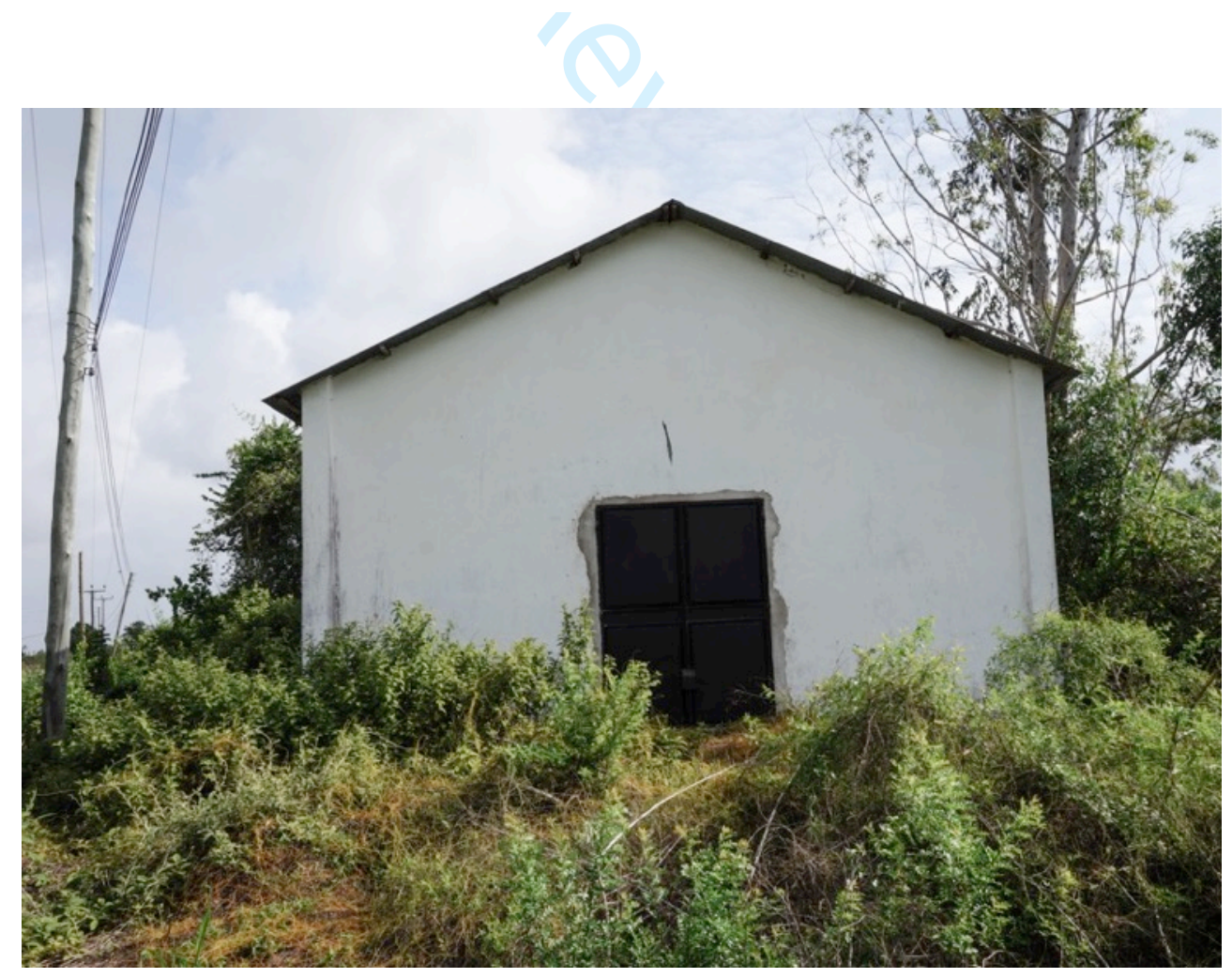

Figure 3. 2017. Pesticide stockpile shed. Built in 1996 with funding from the Swedish International Development Agency. This building replaced a storage shed that collapsed in the mid-1990s. Vikuge, Tanzania. Photographer: author. 


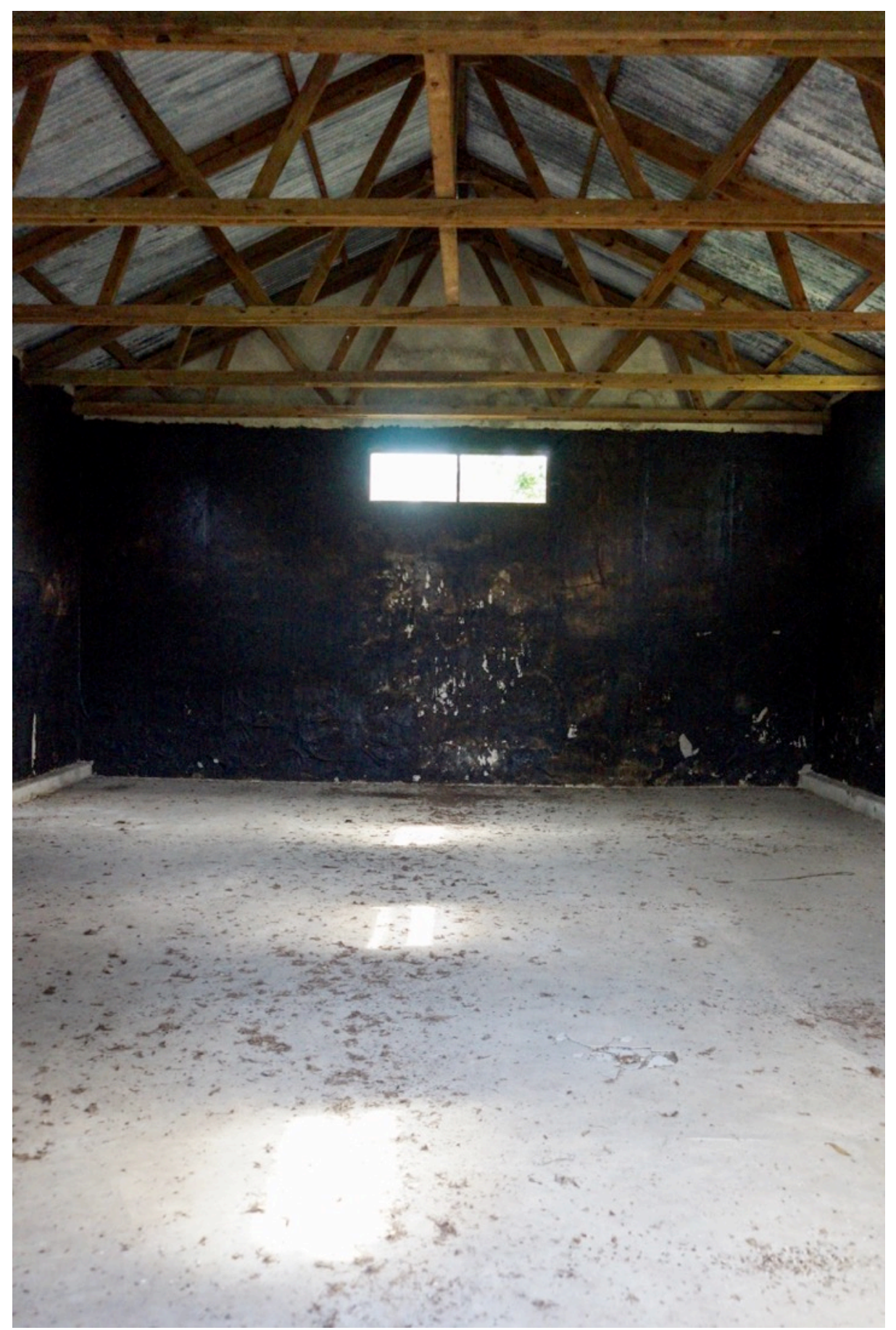

Figure 4. 2017. Interior of pesticide stockpile shed. Vikuge, Tanzania. Photographer: author. 


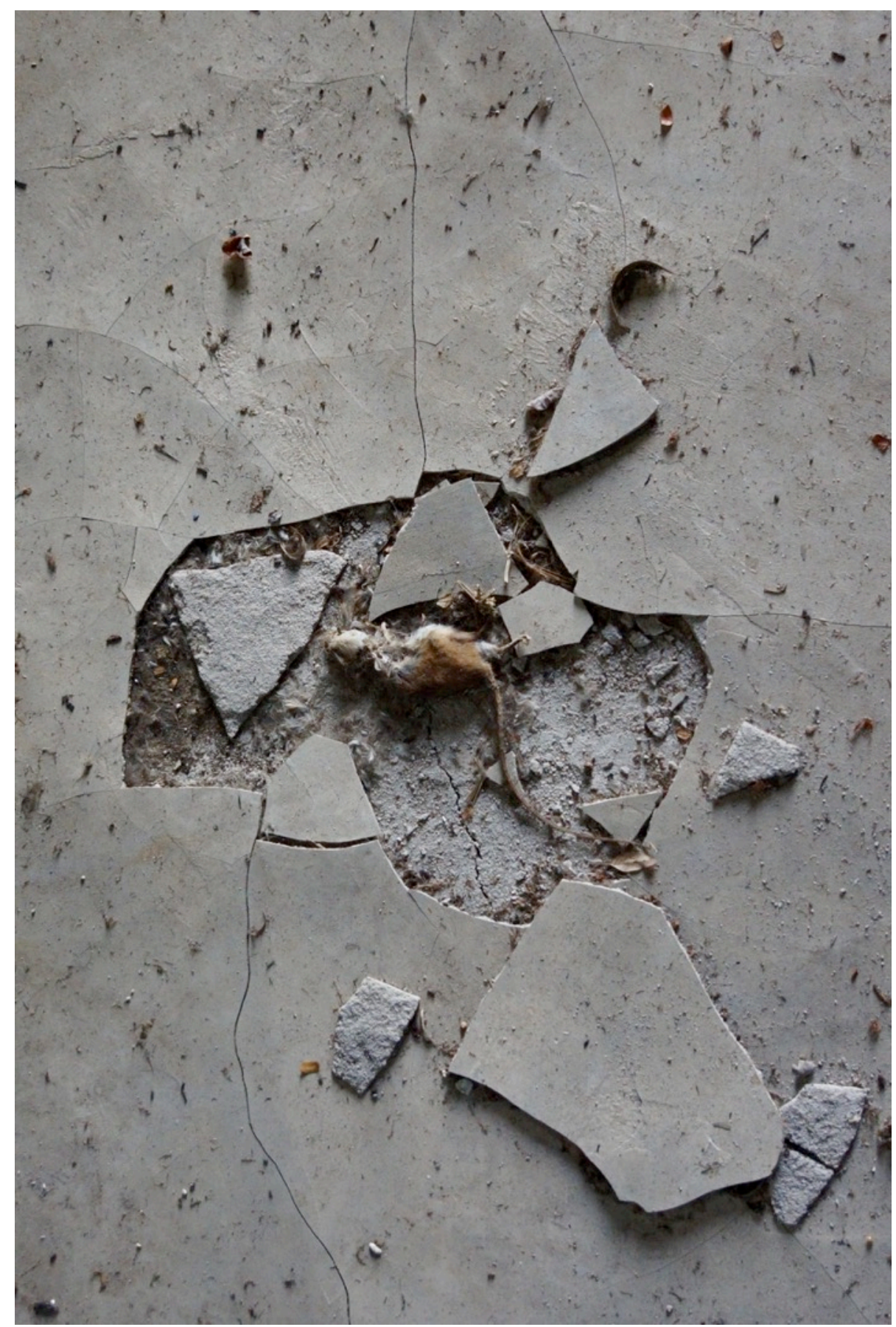

Figure 5. 2017. Dead rat, plant matter, and insects on concrete floor of stockpile shed. Vikuge, Tanzania. Photographer: author. 
The photographs and videos in Veolia's remediation archive are part of a formal accounting process; a set of documentation practices shaped by environmental conventions and regulations on the movement of hazardous materials. The project leader was self-conscious of the aesthetic quality of his photographs as these images not intended for (general) public circulation. In addition to photographs, the project archives include scanned copies of waste packing certificates, risk management plans, and government permits allowing the shipment of hazardous materials through territorial waters. For this team, the documents and photographs were a crucial way of demonstrating to the World Bank that they successfully completed their contract to contain and dispose of the obsolete pesticides. They are the only evidence of remediation. Although I was not permitted to distribute the video, I was permitted to describe it in my research. James offered stills, which feature in the coming pages, that he approved for circulation (the names of the Veolia team have been anonymised for this paper).

These visual representations are an effort to present the team's mastery over the material world. The institutional reports through which they are distributed are a fundamental part of their capacity to speak for the stockpile; they gain their truth-power and authority from the space of circulation (cf. Rose 2003). However, photographs can also have unintentionally aesthetic effects (Harper 2003) and James was very aware of this. While these videos depict competent workers adhering to standard operating procedures, they also illustrate the fragility of human life and the permeability of bodies. They reveal that the task of removal is unavoidably messy, and open questions over the extent to which sites are 'cleanable'. Pesticides are volatile and difficult to handle. Abstracted from the discursive field of the archive, these videos can be read as failures of removal rather than a success. 


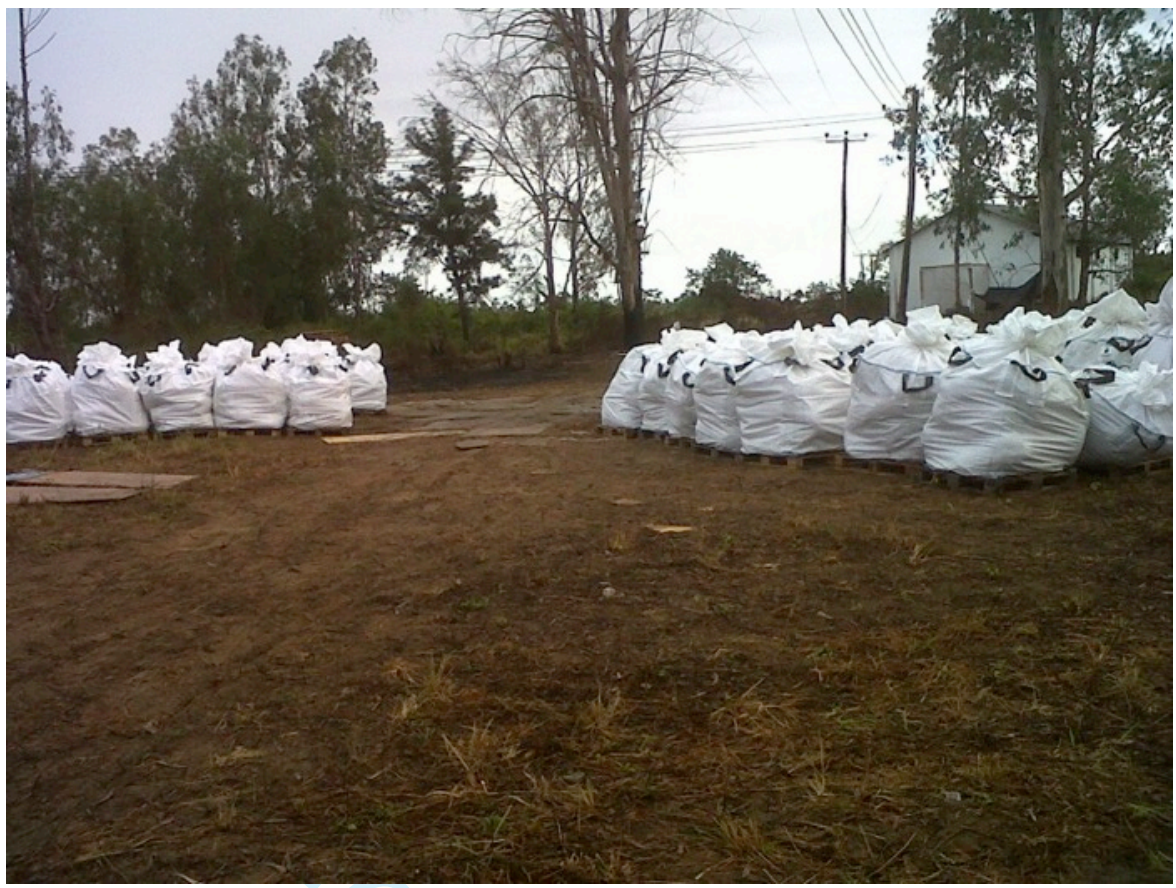

Figure 6. 2012. Pesticide stockpile packed in flexible bulk containers. Awaiting shipment to Poland for incineration. Vikuge, Tanzania. Photographer: Alan. Source: Veolia archive in Nantgarw, Wales.

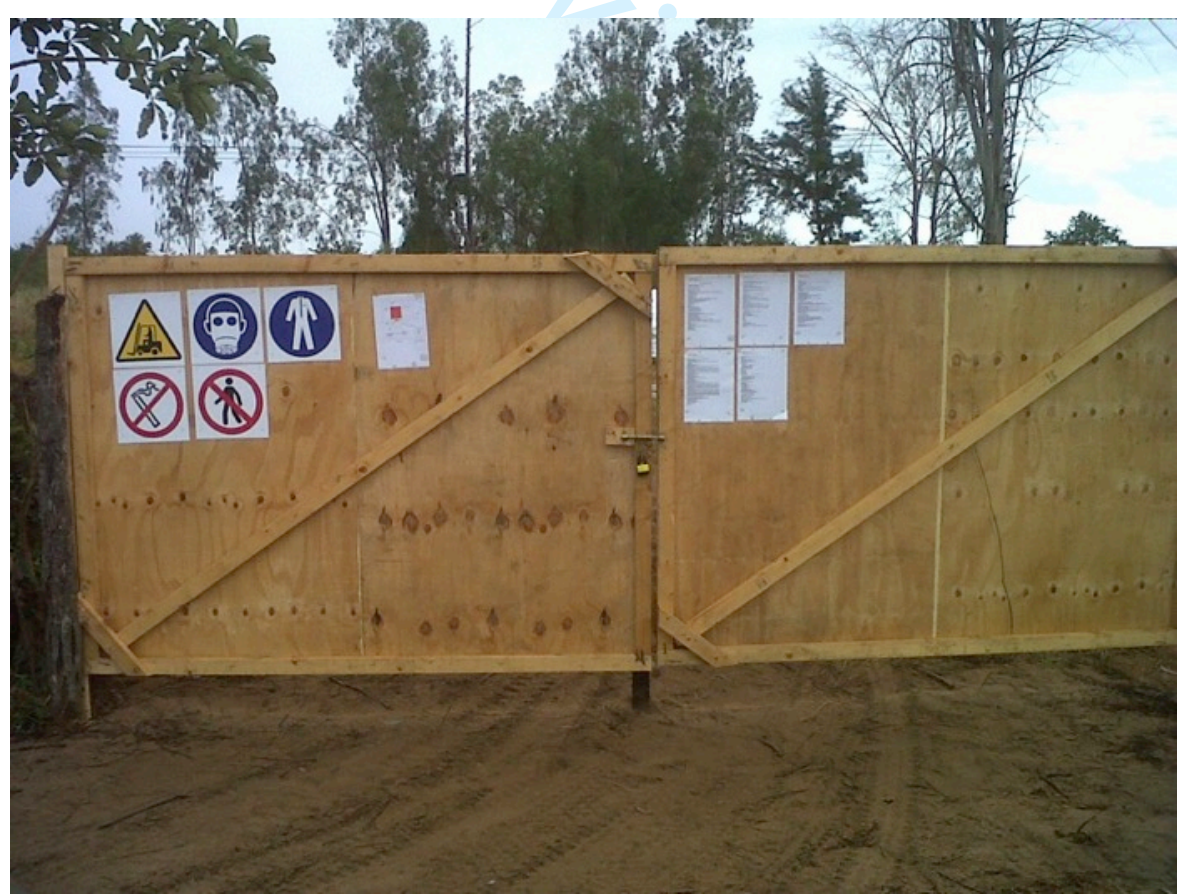

Figure 7. 2012. Temporary plywood gate at entrance to the stockpile site during the removal process. Vikuge, Tanzania. Photographer: Alan (removal project manager). Source: Veolia archive in Nantgarw, Wales. 


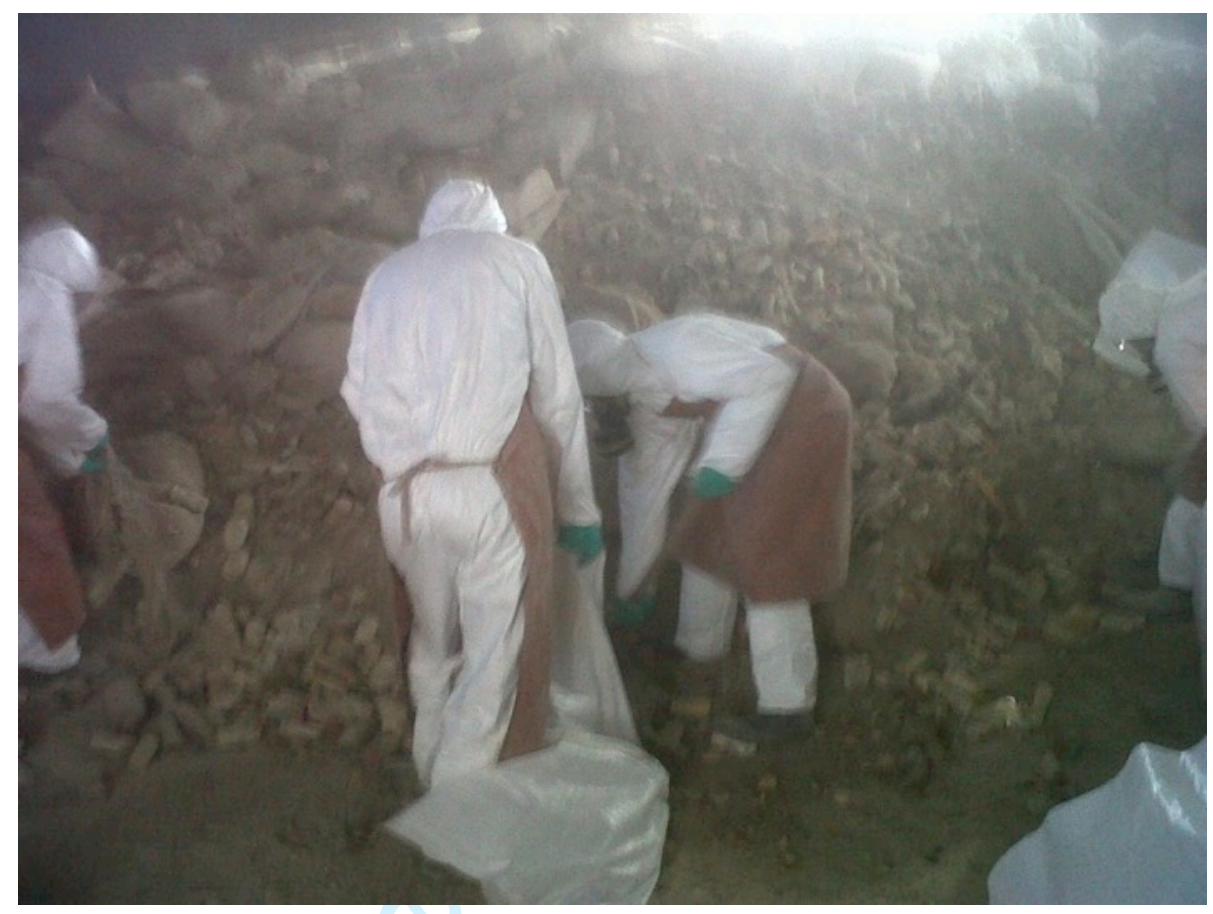

Figure 8. Workers shovelling pesticides into new bags inside stockpile shed. Vikuge, Tanzania. Still from a video filmed by Alan. Source: Veolia archive in Nantgarw, Wales.

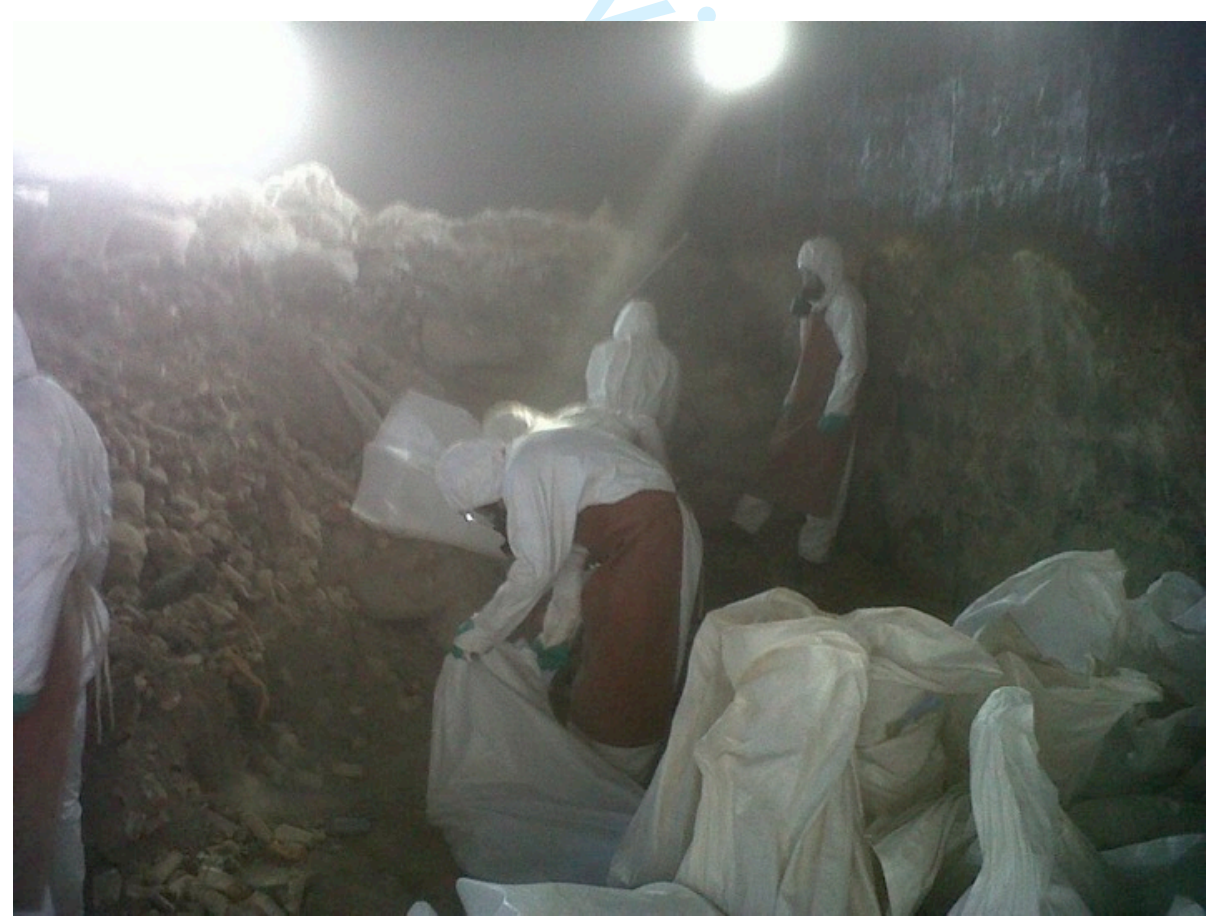

Figure 9. Worker rests against shed wall in the background as others recontain pesticides. Vikuge, Tanzania. Still from video filmed by Alan. Source: Veolia archive in Nantgarw, Wales. 


\begin{abstract}
Bromölla, Sweden. July 2016.
Henrik spends the academic break in his summer house in the south of Sweden. During my stay, we had a lengthy conversation about the Vikuge stockpile in his holiday home-office (his children's old bedroom), where he showed me photographs from his fieldwork at Vikuge on his desktop computer: pictures of dead animals, crumbling sacks of pesticide, fragments of plastic in soil, contaminated wells, and colleagues wearing plastic covers over their boots. We discussed the extent of contamination in the village and the difficulty of knowing the full range of compounds at the site. I recognised some photographs from Henrik's publications -- but the vast majority have never been circulated. He downloaded photos onto my flash drive and asked me to cite him in any publications that emerged from my research.
\end{abstract}

Henrik's photographs of the stockpile have remained in their folders for over a decade. Most have not been circulated beyond his research team. The images are strikingly ordinary. The photograph which opened this paper depicts his colleagues pointing, scratching, waiting, and noting. Their attentiveness to the absence of vegetation in the foreground suggests something significant is occurring, but taken out of the context of Henrik's computer, it would be difficult to imagine what exactly these photographs are depicting. When considered alongside each other, Henrik's mass of faded photographs create a rich tapestry of the Vikuge stockpile site and an account of the violent effects of the stockpile. However, these images of dead animals do not make their way into research papers. Photography is not a formal part of the epistemological practice of chemistry, but it still performs an important function in fieldwork.

Much like my own fieldwork practices, Henrik's photographs have a processual function as field notes. They are also an informal index of the site's toxicity, indicating a concern with effects; registering toxicity through death and absences. It seems environmental chemists visualise contaminated spaces relationally -- reflecting Barry's (2005) argument that chemistry is a uniquely relational discipline. Although this visual practice is not part of chemistry, photography is also used as evidence of the stockpile's presence in publications. Chemistry papers deploy more bounded depictions of pesticides in their containers (e.g. Elfvendahl et al. 2004). They are used to give solidity to the site, and there is an explicit presumption that the representations are truthful as they are located in an academic paper (cf. Rose 2003). The photographs included in this photo essay are the excesses of science. They bear witness to death at the site, but they are not the objects of analysis. Withheld from circulation, they gather digital dust in abandoned files and folders. 


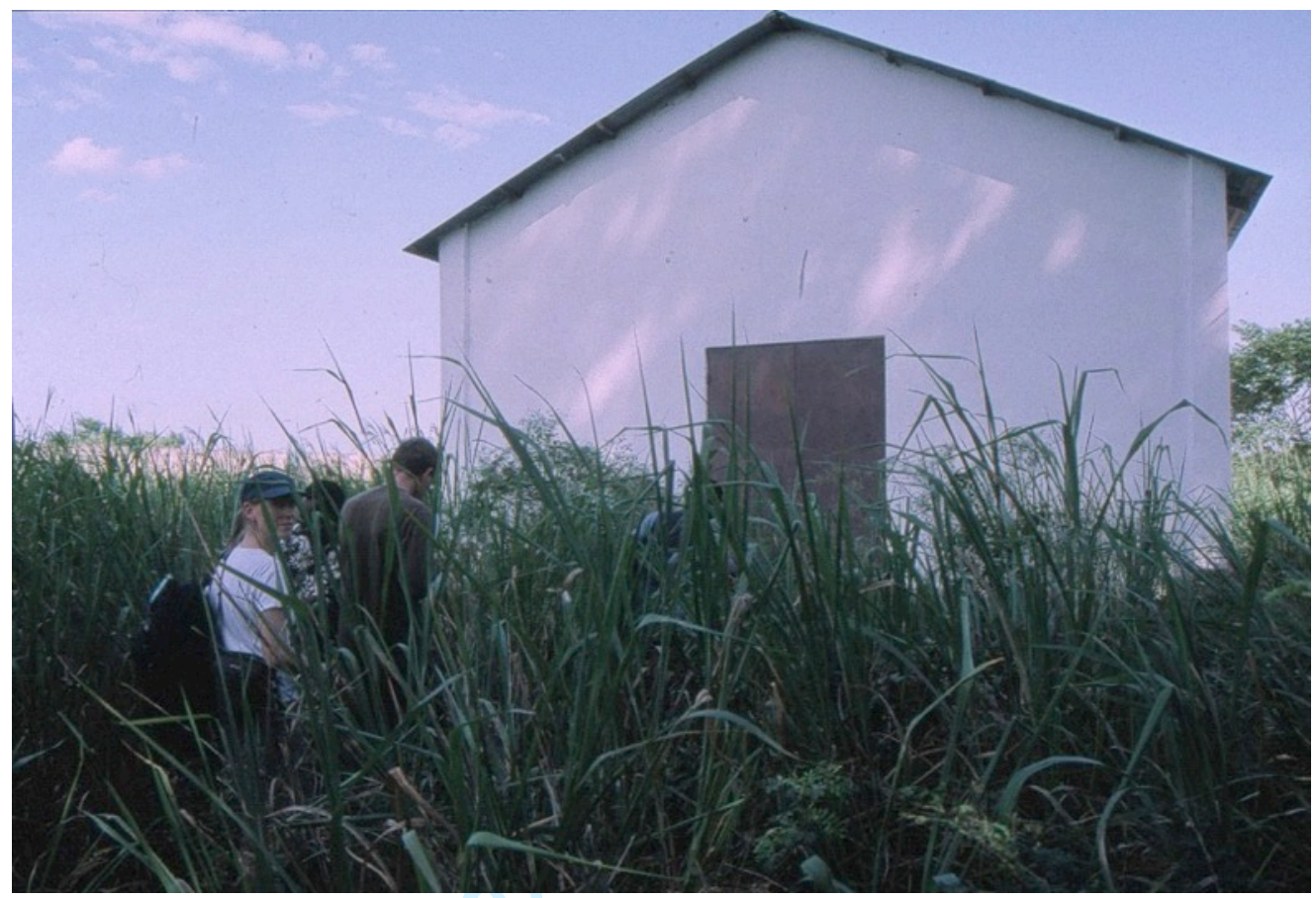

Figure 10. 2002. Environmental chemists at stockpile site during research field trip. Vikuge, Tanzania. Photographer: Henrik Kylin. Source: scanned copy from Henrik's digital research archive in Bromölla, Sweden.

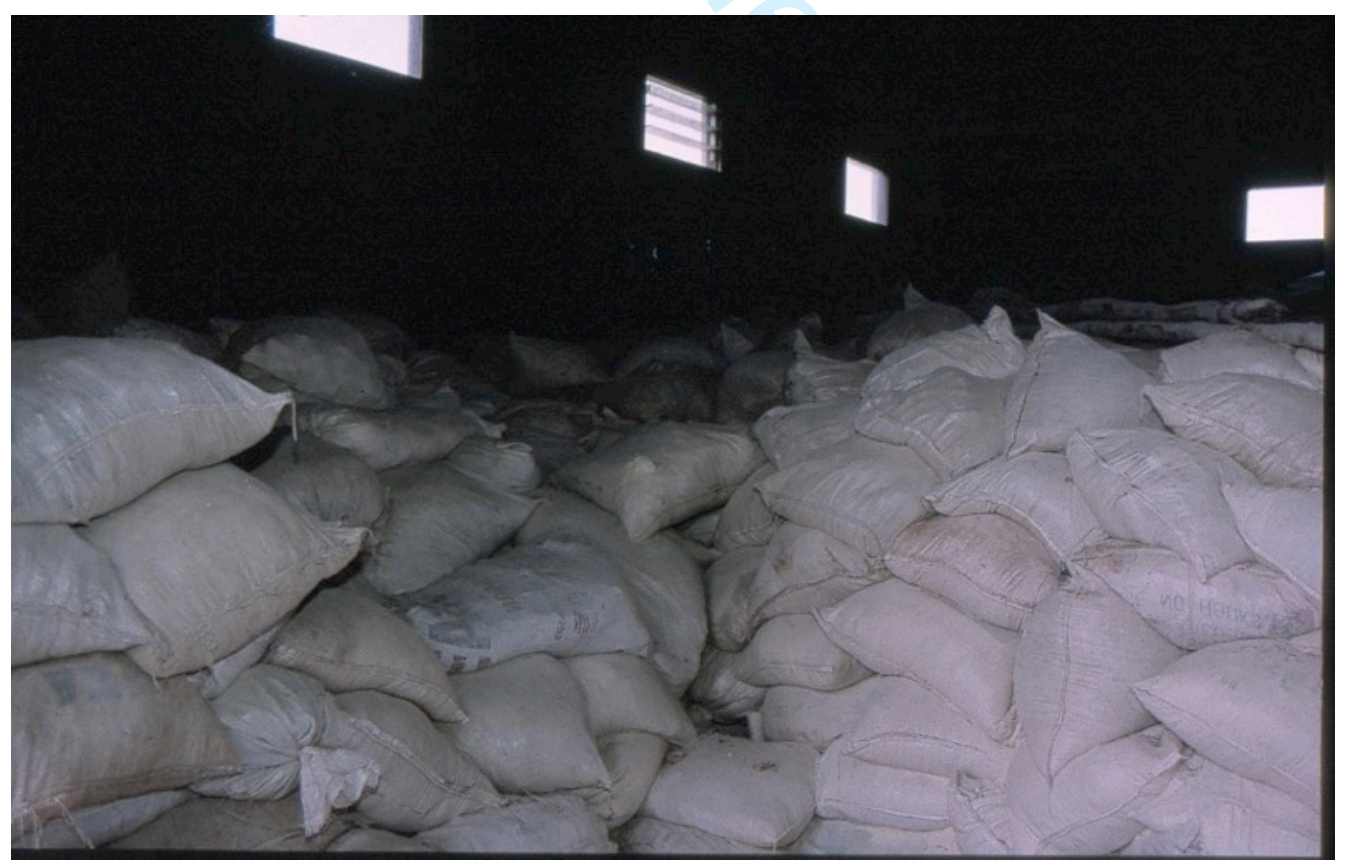

Figure 11. 2002. Interior of pesticide stockpile shed. Vikuge, Tanzania. Photographer: Henrik Kylin. Source: scanned copy from Henrik's digital research archive in Bromölla, Sweden 


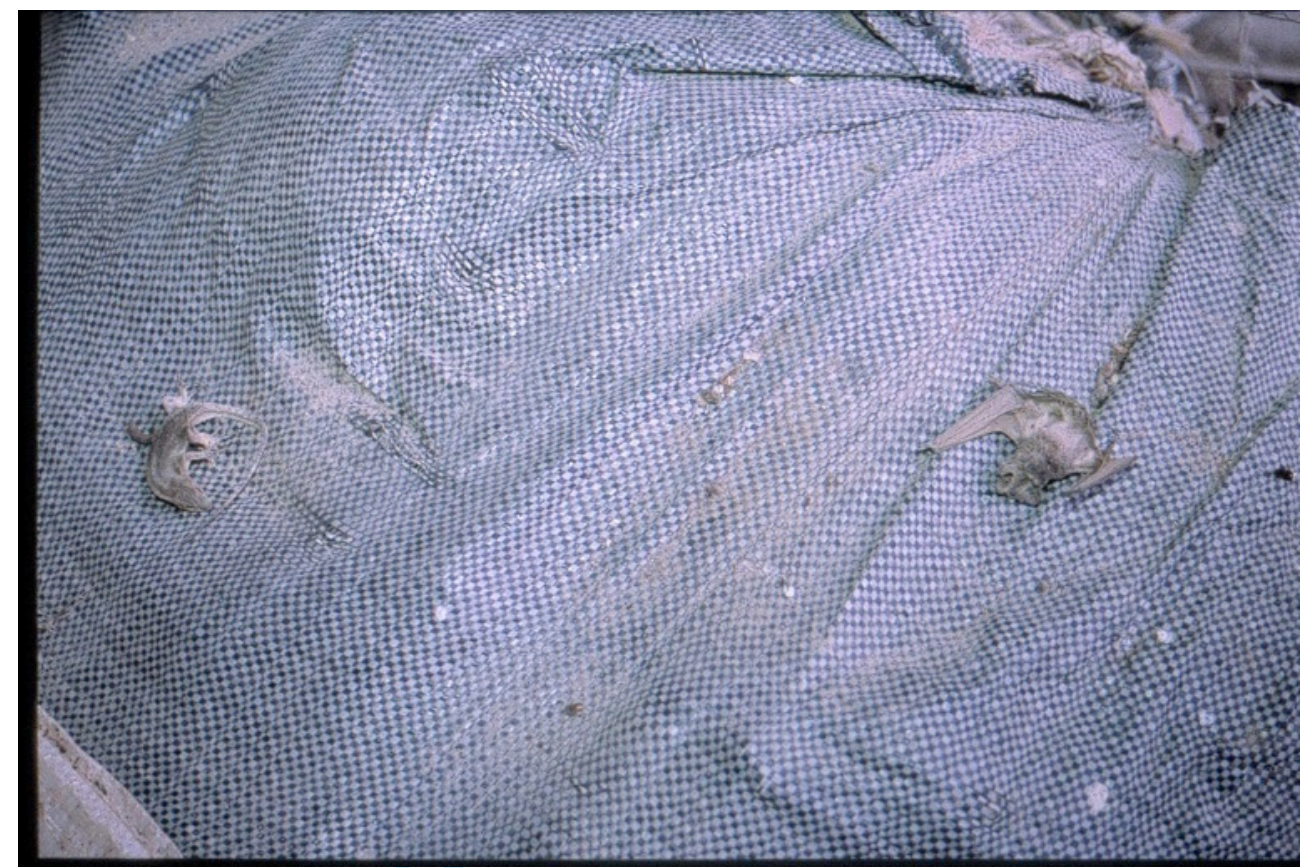

Figure 12. 2002. Dead lizard (left) and bat (right) on woven plastic sack, filled with pesticide containers inside stockpile storage shed. Vikuge, Tanzania. Photographer: Henrik Kylin. Source: scanned copy from Henrik's digital research archive in Bromölla, Sweden.

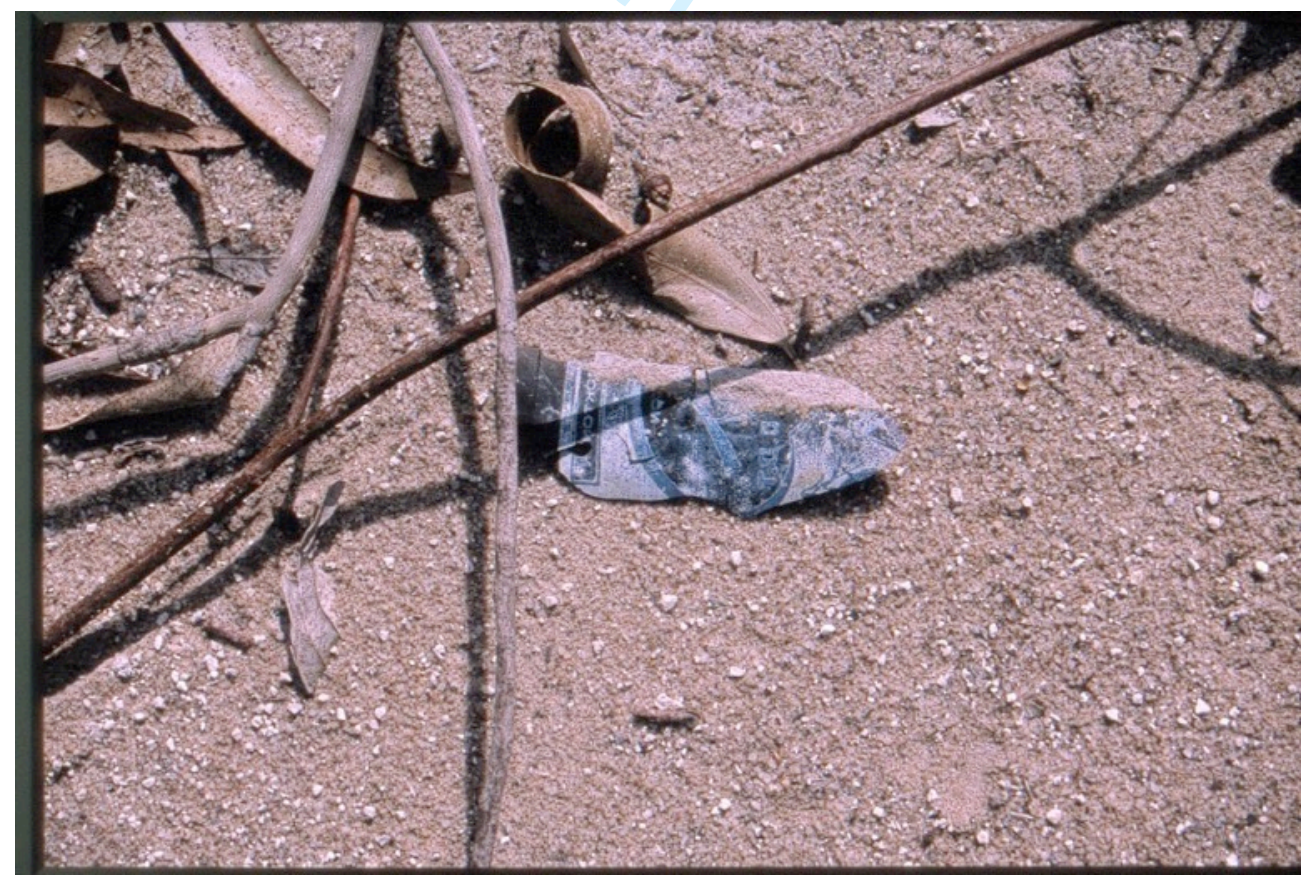

Figure 13. 2002. Fragment of a plastic DDT container on contaminated soil at the perimeter of the stockpile site. Vikuge, Tanzania. Photographer: Henrik Kylin. Source: scanned copy from Henrik's digital research archive in Bromölla, Sweden. 


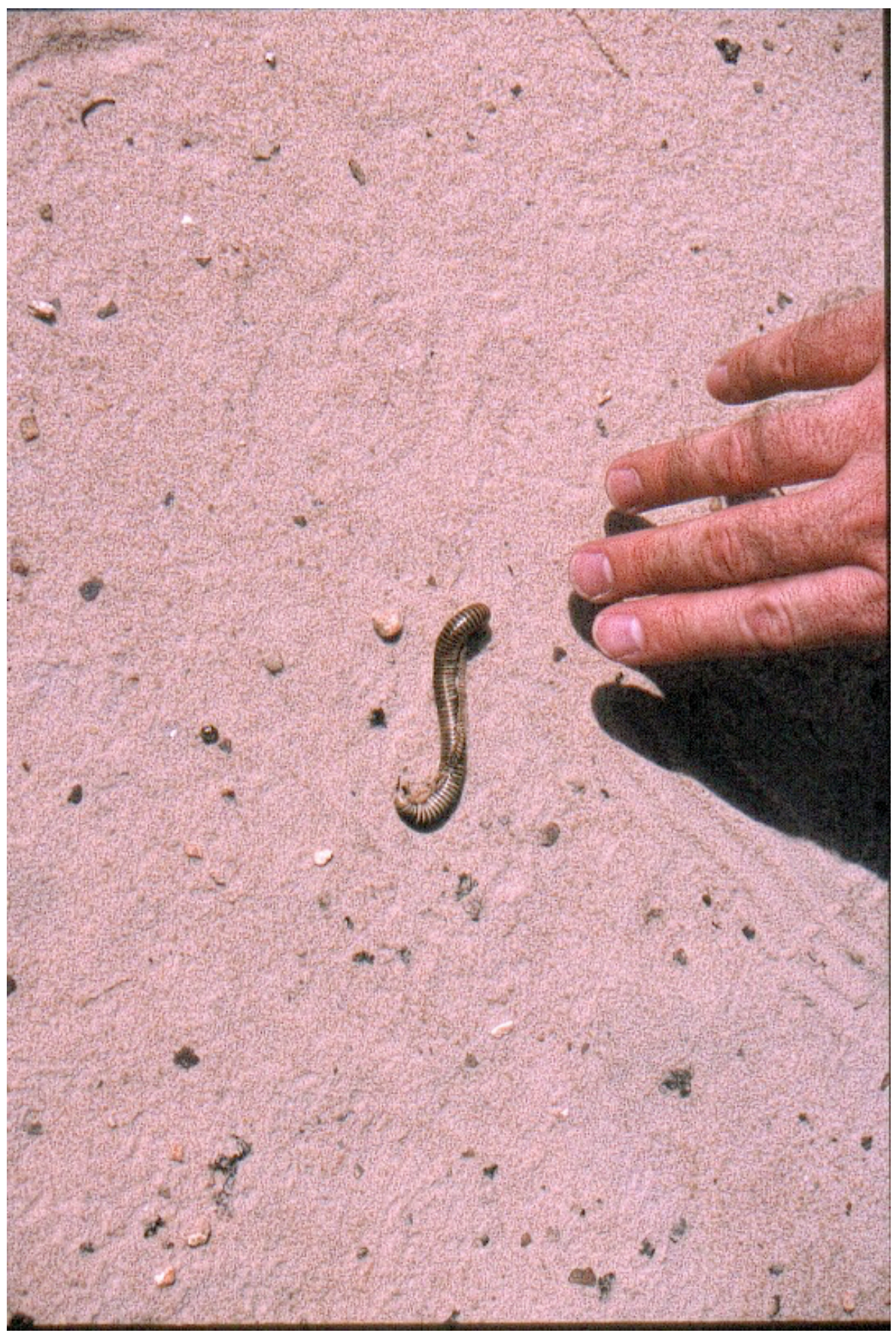

Figure 14. 2002. Chemist points at dead millipede on contaminated soil at the perimeter of the stockpile site. Vikuge, Tanzania. Photographer: Henrik Kylin. Source: scanned copy from Henrik's digital research archive in Bromölla, Sweden 


\section{EXCESSES OF CHEMISTRY}

The photographs assembled in this paper are awkward and often unremarkable. They are outof-focus, unevenly framed, ambiguous, and are losing their detail through successive rounds of digital mediation -- scanning, downloading, cutting, and pasting. These incomplete visual qualities have excesses of meaning that afford alternative readings when the photographs are removed from the authoritative space of the report or the archive. In this way, this visual geography contrasts with critiques of official photographic archives (Margolis 2008). Juxtaposing these routine photographs 'decentres' the site (Law 2002) and expands its spatiotemporalities, materialities, and bodily entanglements. This creates a more materially faithful understanding of hazardous spaces. By photographically approaching hazardous sites as always changing, distributed, and elusive spaces, this paper unsettles the ways in which photographs are deployed as 'raw' evidence (Kearnes 2000) of the material properties of industrial chemicals. In chemistry, as in photography, the site can ultimately only be known through fragments: small samples of matter, which are tested for a narrow handful of compounds, across a very bounded space, within an extremely limited timescale. The assembled photographs presence the partial work of research and the messiness of remediation.

This paper is an ethnographic intervention in the role of photography in apprehending the elusive materialities of chemicals. More broadly, it is an effort to elevate the role of photography in fieldwork. Perhaps the most important question which lingers throughout this paper is the why I have been entrusted with unpublished materials from ostensibly private archives. In downloading their files and photographs onto my flashdrive, Henrik and James are passing on a sense of obligation to publish them. My work poses questions that they cannot afford to ask in their interventions. In many ways these visual methods enabled them to transgress the boundaries of their work, which are routinely reinforced through discipline and standard operating procedures (cf. Sweetman 2009). Considering the paper's concern with excess, it seems appropriate to conclude with some questions rather than answers: What unintended possibilities do routine photographies have outside of their procedural contexts? What does an attentiveness to more ordinary representations in extraordinary circumstances generate? And in what ways can photographic practice create new ways of sensing elusive materials that resist visual representation?

\section{ACKNOWLEDGEMENTS}

I would like to thank Ian Cook, Tim Edensor, Vickie Zhang, David Bissell, and Max Liboiron for their generative feedback on this piece in its various forms and iterations. I am also indebted to the reviewer and editor for comments and critiques that have greatly improved the quality of this work and expanded its potential contribution. This photo essay would ultimately not be possible without the generosity of the chemists and disposal technicians who participated in this research. 
Anaïs, S. and W. Walters, 2016. Hazardous material photography: an interview with Paul Shambroom. cultural geographies 23 (1):159-168. doi: 10.1177/1474474015582171.

Asselin, M. 2017. Monsanto: A Photographic Investigation. Dortmund: Verlag Kettler Press.

Barbash, J. E. 2014. The Geochemistry of Pesticides. In Treatise on Geochemistry, eds. Heinrich D Holland and Karl K Turekian, 535-572. Oxford: Elsevier.

Barry, A. 2005. Pharmaceutical Matters. Theory, Culture \& Society 22 (1):51-69. doi: 10.1177/0263276405048433.

Berger, J. 2013. Understanding a Photograph. London: Penguin Books.

Bissell, D. 2009. Visualising everyday geographies: practices of vision through travel - time. Transactions of the Institute of British Geographers 34 (1):42-60. doi: 10.1111/j.14755661.2008.00326.x.

Clapp, J. 2001. Toxic Exports: The Transfer of Hazardous Wastes from Rich to Poor Countries. Ithaca and London: Cornell University Press.

Conohar, S. 2017. Photographing mining pollution in gold rush: California. Photographies 10 (2):189-209. doi: 10.1080/17540763.2017.1289116.

Cook et al. 2004. Follow the thing: Papaya. Antipode 36 (4):642-664. doi: 10.1111/j.14678330.2004.00441.x.

Crang, M. 1996. Envisioning urban histories: Bristol as plampsest, postcards, and snapshots. Environment and Planning A: Economy and Space 28 (3):429-452. doi: 10.1068/a280429.

Crang, M. 2010. The death of great ships: photography, politics, and waste in the global imaginary. Environment and Planning A 42 (5):1084-1102. doi: 10.1068/a42414.

Crang, M. 2012. Tristes Entropique: Steel, Ships and Time Images for late Modernity. In Visuality/Materiality: Images, Objects and Practices, ed. G. Rose and D. P. Tolia-Kelly, 5972. Farnham: Ashgate.

Davies, T. 2013. A visual geography of Chernobyl: double exposure. International Labor and Working-Class History 84:116-39. doi: 10.1017/S0147547913000379.

Davies, T. 2018. Photography and toxic pollution: exposing a chemical company. Science as Culture doi: 10.1080/09505431.2018.1523885.

Davis, F. R. 2014. Banned: A History of Pesticides and the Science of Toxicology. New Haven and London: Yale University Press.

de Certau, Michel. 1984. The Practice of Everyday Life. Berkley, CA: University of California Press.

Degen, M., C. DeSilvey, and G. Rose. 2008. Experiencing visualities in designed urban environments: learning from Milton Keynes. Environment and Planning A 40 (8):1901-1920.

Elfvendahl, S., M. Mihale, M. A. Kishimba, and H. Kylin. 2004. Pesticide pollution remains severe after cleanup of a stockpile of obsolete pesticides at Vikuge, Tanzania. Ambio 33(8):503-508. doi: 10.1639/0044-7447(2004)033[0503:pprsac]2.0.co;2. 
FAO. 2002. Sixth FAO Consultation on Prevention and Disposal of Obsolete, and Banned Pesticide Stocks. Food and Agriculture Organization of the United Nations, Rome, Italy.

Gabrys, J. 2017. Monitoring and Remediating a Garbage Patch. In Research Objects in their Technological Setting, ed. B. Bensaude-Vincent, A. Nordmann, A. Schwarz and S. Loeve, 201-214. London: Routledge.

Galt, R. E. 2008. Beyond the circle of poison: Significant shifts in the global pesticide complex, 1976-2008. Global Environmental Change 18 (4):786-799. doi: 10.1016/j.gloenvcha.2008.07.003.

Garrett, B. L. 2014. Worlds Through Glass: Photography and Video as Geographic Method. In Researching the City, ed. K. Ward, 135-152. London: SAGE Publications.

Gatlin, J. 2015. Toxic Sublimity and the Crisis of Human Perception: Rethinking Aesthetic, Documentary, and Political Appeals in Contemporary Wasteland Photography. ISLE:

Interdisciplinary Studies in Literature and Environment 22 (4):717-741. doi:10.1093/isle/isv032.

Giblett, R. 2009. Landscapes of Culture and Nature. Basingstoke: Palgrave Macmillan.

Gregson, N., M. Crang, F. Ahamed, N. Akhter, and R. Ferdous. 2010. Following things of rubbish value: End-of-life ships, 'chock-chocky' furniture and the Bangladeshi middle class consumer. Geoforum 41 (6):846-854. doi: 10.1016/j.geoforum.2010.05.007.

Harper, D. 2003. Framing Photographic Ethnography. Ethnography 4 (2):241-266. doi:10.1177/14661381030042005.

Houston, D. 2013. Environmental Justice Storytelling: Angels and Isotopes at Yucca Mountain, Nevada. Antipode 45 (2):417-435. doi: 10.1111/j.1467-8330.2012.01006.x.

IPEN, and AGENDA. 2005. Contamination of chicken eggs near the Vikuge obsolete pesticides stockpile in Tanzania by dioxins, PCBs and hexachlorobenzene. International POPs Elimination Network, AGENDA For Environment and Responsible Development, and Arnika Association, Dar es Salaam, Tanzania.

Kearnes, M. 2000. Seeing is believing is knowing: towards a critique of pure vision. Australian Geographical Studies 38(2): 332-340. doi: doi.org/10.1111/1467-8470.00121.

Krupar, S. R. 2013. Hot Spotter's Report: Military Fables of Toxic Waste. Minneapolis and London: University of Minnesota Press.

Law, J. 2002. Aircraft stories: Decentering the object in technoscience. Durham: Duke University Press.

Law, J. and J. Whittaker. 1988. On the art of representation: notes on the politics of visualisation. In Picturing Power: Visual Depiction and Social Relations, ed. G. Fyfe and J. Law, 160-183. London: Routledge.

Lepawsky, J. 2015. Are we living in a post-Basel world? Area 47(1): 7-15. doi: 10.1111/area.12144

Liboiron, M. 2015. Redefining pollution and action: The matter of plastics. Journal of Material Culture 21 (1):1-24. doi: 10.1177/1359183515622966.

Lorimer, H. 2005. Cultural geography: the busyness of being 'more-than-representational'. 
Progress in Human Geography 9 (1): 83-94. doi: 10.1191/0309132505ph531pr.

Margolis, E. 2008. Picturing labor: A visual ethnography of the coal mine labor process. Visual Sociology 13(2): 5-35. doi: 10.1080/14725869808583792.

Misrach, R. and K. Orff. 2012. Petrochemical America. New York: Aperture.

Moore, S. A., R. E. Roth, H. Rosenfeld, E. Nost, K. Vincent, M. R. Arefin, and T. M. A. Buckingham. 2017. Undisciplining environmental justice research with visual storytelling. Geoforum. doi: 10.1016/j.geoforum.2017.03.003.

Ngai, S. 2012. Our aesthetic categories: Zany, cute, interesting. Cambridge, MA: Harvard University Press.

Nixon, R. 2011. Slow Violence and the Environmentalism of the Poor. Cambridge MA and London: Harvard University Press.

Peeples, J. 2011. Toxic Sublime: Imaging Contaminated Landscapes. Environmental Communication 5 (4):373-392. doi: 10.1080/17524032.2011.616516.

Pikner, T. and J. S. Jauhiainen. 2014. Dis/appearing waste and afterwards. Geoforum 54:3948. doi: 10.1016/j.geoforum.2014.03.009.

Pratt, LA. 2011. Decreasing dirty dumping? A Re-evaluation of toxic waste colonialism and the global management of transboundary hazardous waste. William \& Mary Environmental Law and Policy Review 35(2): 582-623.

Ray, S. J. 2016. Environmental Justice, Vital Materiality, and the Toxic Sublime in Edward Burtynsky's Manufactured Landscapes. GeoHumanities 2 (1):203-219. doi:

10.1080/2373566X.2016.1167615.

Romero, A. M., J. Guthman, R. E. Galt, M. Huber, B. Mansfield, and S. Sawyer. 2017.

Chemical Geographies. GeoHumanities 3 (1):158-177. doi:

10.1080/2373566X.2017.1298972.

Rose, G. 2003. On the need to ask how, exactly, is geography "visual"? Antipode 35 (2):212221. doi: $10.1111 / 1467-8330.00317$.

Rose, G. 2016. Visual Methodologies: An Introduction to Researching with Visual Materials. 4th ed. London: SAGE Publications.

Rose, G. and D. P. Tolia-Kelly. 2012. Visuality/Materiality: Introducing a Manifesto for Practice. In Visuality/Materiality: Images, Objects and Practices, ed. G. Rose and D. P. Tolia-Kelly, 1-12. Farnham: Ashgate.

Rosenfeld, H., S. A. Moore, E. Nost, R. E. Roth, and K. Vincent. 2018. Hazardous Aesthetics: A "Merely Interesting" Toxic Tour of Waste Management Data. GeoHumanities 4 (1):262-281. doi: 10.1080/2373566X.2017.1423235.

Shapiro, N. 2015. Attuning to the chemosphere: Domestic formaldehyde, bodily reasoning, and the chemical sublime. Cultural Anthropology 30 (3):368-393. doi: 10.14506/ca30.3.02.

Shapiro, N. and E. Kirksey. 2017. Chemo-ethnography: An introduction. Cultural Anthropology 32 (4):481-493. doi: 10.14506/ca32.4.01.

Sontag, S. 2003. Regarding the Pain of Others. London: Penguin Books. 
Sweetman, P. 2009 Revealing habitus, illuminating practice: Bourdieu, photography and visual methods. The Sociological Review 57(3): 491-511. doi: 10.1111/j.1467-

954X.2009.01851.x.

ANGELIKI BALAYANNIS is a Lecturer in Human Geography in the Department of Geography at the University of Exeter, Exeter, EX4 4RJ. Email: A.A.Balayannis@exeter.ac.uk. She recently completed a Rutherford Fellowship in the Institute of Environment, Health and Societies, at Brunel University London. Her research interests include material cultures and politics, chemical geographies, and life at hazardous sites. 